Revue d'histoire de l'Amérique française

REVUE D.HISTOIRE DE L'AMÉRIQUE FRANÇAISE

\title{
MURRAY, Florence B. (Ed.), Muskoka and Haliburton (1615-1875), A collection of Documents, Toronto, The Champlain Society, 1963, 445 p.
}

\section{Jacques Gouin}

Volume 17, numéro 1, juin 1963

URI : https://id.erudit.org/iderudit/302259ar

DOI : https://doi.org/10.7202/302259ar

Aller au sommaire du numéro

Éditeur(s)

Institut d'histoire de l'Amérique française

ISSN

0035-2357 (imprimé)

1492-1383 (numérique)

Découvrir la revue

Citer ce compte rendu

Gouin, J. (1963). Compte rendu de [MURRAY, Florence B. (Ed.), Muskoka and Haliburton (1615-1875), A collection of Documents, Toronto, The Champlain Society, 1963, 445 p.] Revue d'histoire de l'Amérique française, 17(1), 113-115. https://doi.org/10.7202/302259ar d'utilisation que vous pouvez consulter en ligne.

https://apropos.erudit.org/fr/usagers/politique-dutilisation/ 


\section{LIVRES ET REVUES}

MURRAY, Florence B. (Ed.), Muskoka and Haliburton (16151875), A collection of Documents, Toronto, The Champlain Society, 1963, 445 p.

Ce sixième volume de la série ontarienne des Publications de la Société Champlain réunit plus de trois cents documents, datés de 1615 à 1875 , se rapportant à cette région de l'Ontario qui englobe le district de Muskoka et le comté d'Haliburton. Bien que la majorité de ces documents intéressent avant tout l'Ontario anglophone, il reste que bon nombre d'entre eux évoquent la marque impérissable qu'ont laissée nos ancêtres français et canadiens-français dans cette partie du Canada. Comme quoi, le Canada français est intimement et indissolublement lié à l'ensemble du continent nord-américain tout entier, malgré tout ce qu'on pourrait dire ou souhaiter de part et d'autre de la frontière ethnique qui sépare trop souvent le Canada anglais du Canada français. Et pourtant, les faits de notre histoire commune devraient nous commander une union plus intime. Cette collection de documents en est une autre preuve irréfutable.

Ainsi, lit-on dans l'avant-propos de John P. Robarts, premier ministre de l'Ontario, on peut retracer dans cet ouvrage le progrès de cette région ontarienne jusqu'à 350 ans en arrière, alors que des Pères Jésuites (français évidemment) commencèrent à évangéliser les Indiens nomades de cette partie du continent. Puis, dans une excellente introduction, $\mathrm{M}^{\text {1le }}$ Florence B. Murray, professeur associé de l'Ecole de bibliothéconomie de l'université de Toronto, et éditrice de cette collection de documents, nous rappelle que c'est un jeune Français du nom d'Etienne Brûlé qui, la première fois, en 1610 ou 1611, explora la région de Muskoka et d'Haliburton. Ensuite, ce furent le Père Joseph Le Caron et dix Français, à l'été de 1615. Ces derniers étaient suivis, peu de temps après, à la fin de juillet 1615, par nul autre que Champlain lui-même. C'est de lui d'ailleurs que nous a été transmise la première description de cette région. Quelques années plus tard, soit en 1623-1624, c'était un Récollet du nom de Gabriel Sagard, qui parcourait cette région, et qui faisait le récit de son voyage dès son retour en France. En 1625, d'autres Pères jésuites commençaient leur 
travail d'évangélisation chez les Hurons de cette partie du pays. Dans les Relations, on relève deux missions à cette époque, celles de Ste-Elizabeth et de St-Esprit, la première ayant débuté entre 1640 et 1644 pour desservir les Algonquins chassés de la vallée du St-Laurent par les Iroquois, la seconde ayant été établie pour les Algonquins du lac Nipissing et d'autres bandes qui hivernaient dans les environs. C'est le Père Claude Pijart qui inaugura cette dernière mission le 8 mai 1641, où il passa plusieurs années de labeur, aidé à l'occasion par le Père Léonard Garreau.

Après la dispersion des Hurons en 1649, les Pères jésuites suivirent leurs troupeaux jusqu'aux îles de la baie Georgienne et aux forêts où ils s'étaient réfugiés. Aucun document n'a été retrouvé qui puisse établir la présence des Blancs après la dispersion des Hurons. Mais, en 1669, un autre Français, du nom de Jean Paré, laissait sa marque dans cette région, puisque le tracé de son voyage figure sur la carte de Galinée, datée de 1670. Quelques années plus tard, c'est la trace de Cavelier de La Salle que nous retrouvons. Ensuite, c'est le fameux baron de Lahontan, de regrettable mémoire. Autre fait intéressant à noter, c'est que, sur une carte datée de 1679, le lac Simcoe était indiqué comme étant le «Lac de Taronto (sic)»; sur une autre carte de 1680 , il est de nouveau indiqué comme étant le «Lac de Tarenteau (sic)»; encore, en 1688, une autre carte l'indiquait comme étant le «Lac Taronto (sic) 》. Ce qui expliquerait peut-être la prononciation « Tarento » que nous relevons encore de nos jours chez certains Canadiens français. Petit détail que les linguistes auraient peut-être intérêt à élucider.

En 1785, on relève un autre nom français lié à cette région, soit celui du Chevalier de Rocheblave qui, dans un mémoire aux autorités britanniques, réclamait, comme indemnisation de guerre, un territoire qui eût été le premier du district de Muskoka à être concédé. Sa demande ne fut pas agréée, il va sans dire.

Après le traité de Paris de 1763 , et surtout après le traité de Versailles de 1783, avec l'afflux des loyalistes dans cette région, on perd rapidement toute trace d'origine française dans ce qui allait devenir une partie du Haut-Canada. Mais, encore à la fin du XVIII' siècle, le plus grand trafiquant de fourrures de la région est un nommé Jean-Baptiste Constant (probablement un Canadien français). On relève également le nom de Quetton St-George, royaliste français émigré au Canada en 1798. $\mathrm{Au}$ début du XIX ${ }^{\mathrm{e}}$ siècle, on relève encore les noms de Jean- 
Baptiste Sylvestre, père et fils, tous deux Canadiens français, et importants trafiquants de fourrures dans cette région. Un autre Canadien français, Jean-Baptiste Rousseau, laissa une marque importante dans la même région, à cette époque.

A compter du $\mathrm{XIX}^{\mathrm{e}}$ siècle, la documentation présentée dans ce volume se confond de plus en plus avec l'histoire proprement dite de l'Ontario anglophone. Il reste que l'ensemble de cet ouvrage, d'un intérêt historique indéniable pour l'Ontario, ne saurait manquer d'intéresser également le Canada français. Les quelques exemples ci-dessus devraient suffire à le démontrer.

JACQUES GOUIN, Chef adjoint, Traduction, Ministère de la Défense nationale, Ottawa. 